\title{
Managing a mega-project to explore and enhance careers: insights from Global Entrepreneurial Talent Management 3
}

\author{
Alison Pearce \\ Brian Harney \\ Dublin City University, brian.harney@dcu.ie \\ Mark Bailey
}

See next page for additional authors

Follow this and additional works at: https://arrow.tudublin.ie/ascnetoth

Part of the Business Administration, Management, and Operations Commons

\section{Recommended Citation}

Pearce, Alison; Harney, Brian; Bailey, Mark; Dziewanowska, Katarzyna; Bosak, Janine; Pease, Peter; Stalker, Brenda; Skoumpopoulou, Dimitra; Doyle, Paul; Clegg, Samuel; Shokri, Alireza; Crane, Suzanne; O'Donnell, Susan; Quan, Rose; Ko, Ilsang; Mihelič, Katarina K.; Kaše, Robert; Černe, Matej; Brückner, Julie; McMackin, John; Wu, Szu-Hsin; Hernandez, Jose Aldo Valencia; and Sun, Huan, "Managing a mega-project to explore and enhance careers: insights from Global Entrepreneurial Talent Management 3" (2021). Other. 4.

https://arrow.tudublin.ie/ascnetoth/4

This Book Chapter is brought to you for free and open access by the Applied Social Computing Network at ARROW@TU Dublin. It has been accepted for inclusion in Other by an authorized administrator of ARROW@TU Dublin. For more information, please contact arrow.admin@tudublin.ie, aisling.coyne@tudublin.ie, gerard.connolly@tudublin.ie. Funder: European Union

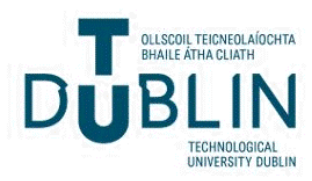




\section{Authors}

Alison Pearce, Brian Harney, Mark Bailey, Katarzyna Dziewanowska, Janine Bosak, Peter Pease, Brenda Stalker, Dimitra Skoumpopoulou, Paul Doyle, Samuel Clegg, Alireza Shokri, Suzanne Crane, Susan O'Donnell, Rose Quan, Ilsang Ko, Katarina K. Mihelič, Robert Kaše, Matej Černe, Julie Brückner, John McMackin, Szu-Hsin Wu, Jose Aldo Valencia Hernandez, and Huan Sun 


\title{
4. Managing a mega-project to explore and enhance careers: insights from Global Entrepreneurial Talent Management 3
}

\author{
Alison Pearce, Brian Harney, Mark Bailey, Katarzyna \\ Dziewanowska, Janine Bosak, Peter Pease, Brenda \\ Stalker, Dimitra Skoumpopoulou, Paul Doyle, \\ Samuel Clegg, Alireza Shokri, Suzanne Crane, Susan \\ O'Donnell, Rose Quan, Ilsang Ko, Katarina K. \\ Mihelič, Robert Kaše, Matej Černe, Julie Brückner, \\ John McMackin, Szu-Hsin Wu, Jose Aldo Valencia \\ Hernandez, and Huan Sun
}

\section{INTRODUCTION}

Contemporary careers are changing, and they face many challenges. This creates a pressing need for innovative research that is cross-cultural and multidisciplinary. Many forces influence careers: shifting expectations, new technology, and institutional and cultural factors that define career success (Kaše et al., 2019). The European Union recognized the significance of enhancing career capabilities to drive innovation and competitiveness, allocating some 6.16 billion euros to researcher training and development under the Horizon 2020 program. This chapter details insights from the Global Entrepreneurial Talent Management 3 project (GETM3). GETM3 is an international, interdisciplinary, research and innovation project which received over one million euros from Research Innovation and Staff Exchange (RISE) Horizon 2020 Marie-Skłodowska-Curie Actions (MSCA), coupled with matched Korean Research Foundation funding. RISE funds short-term, international exchanges of personnel between academic, industrial, and commercial organizations worldwide to develop research capacity. A key objective is to "help people develop their knowledge, skills, and careers, while building links between organizations working in different sectors of the economy, including universities, research institutes, and SMEs" (European Commission, 2019). The goal of providing an infrastructure for individuals to work and research in other countries is to "make the whole world a learning environment" and "break down barriers between academia, industry, and business."

In this this introduction we provide an overview of the GETM3 project, exploring its approach and origins, then outlining the project design, methodology, key levers of implementation, before detailing participant experiences. In so doing our focus is 
not simply to situate the project within the context of career research, but equally, to illuminate how the project itself serves to bridge national, sectoral, disciplinary, methodological, and career life stages as a vehicle for career development. The chapter gives examples of guiding principles and underlying values on the way to best practice. It offers pragmatic reflections on the origins, emergence, and evolution of a research collaboration exploring careers on a grand scale.

\section{Context and Rationale}

GETM3 is a multidisciplinary project bringing together 16 partners from five countries: the United Kingdom, Ireland, Poland, Slovenia, and the Republic of Korea (South Korea). The project was conceived in 2016 and began in 2017. It involves more than 100 staff conducting over 290 month-long international mobility secondments (relocations) across academia and industry. The project team was designed to be multidisciplinary composite of academics, university staff, consultants, and practitioners. The goal for the project was to improve understanding of career expectations, trajectories, and challenges, especially for young employees and their managers/employers. The word entrepreneurial refers to entrepreneurial skills as manifest in creativity, exploration, and positive change. As per the European Commission, the focus is not limited to new ventures, start-ups, and new jobs but also covers "an individual's ability to turn ideas into action" (European Commission, 2008 , p. 7). Focusing on young entrepreneurial talent in particular, careers are understood as a series of ongoing learning cycles founded on career evolution and life-long learning, as opposed to distinct stages of development (Donald et al., 2019; Craig $\&$ Hall, 2011). The project is innovative in its multi-stakeholder approach, working with three stakeholder groups: young people as current students and future graduates, higher education institutions with educators of the future, and employers as future wealth creators. By drawing on insights from students, educators, and employers, the project calls for research to move beyond single stakeholder perspectives and adopt multiple perspectives and approaches.

The GETM3 project examines work that is transnational, trans-sectoral, and transgenerational. Three unique features of the GETM3 project are worth outlining. First, the explicit incorporation of industry partners ensures that GETM3 retains a focus on industry engagement and enhancing practice (described in detail later). This is timely in the context of calls to explore how an understanding of the functioning careers can lead to more effective talent management practice (Crowley-Henry et al., 2019). Second, a multi-level, cross-comparative focus highlights the ecosystem in which career opportunities and challenges are embedded (Baruch \& Rousseau, 2018). Recent research notes the need for "a more fine-grained and nuanced consideration of context in our understanding of career success schemas, as a foundation for understanding subjective career success across national cultures" (Kaše et al., 2020, p.424). The international, comparative focus of GETM3 reflects the global intensity of career challenges. It also links with the European Union and Korean Research Foundation's agenda, including the Bologna Process (harmonization of European HE 
systems), which solidified a shift to student mobility (Brabrand \& Dahl, 2009). This relates to the third feature of GETM3, setting up infrastructure and funds for international mobility. RISE funding is that it affords "a unique opportunity for individuals to expand their horizons, enlarge their networks, receive innovative research training, and develop new career opportunities." (European Commission, 2017). Researcher mobility is key to achieving GETM3 objectives because it strengthens collaboration and knowledge sharing amongst participants, but also brings opportunities for field work and exposure to different work styles and contexts (national culture and economy, sectors, disciplines). It therefore improves the opportunity to study careers from different perspectives. By facilitating collaboration between experienced and less experienced researchers, as well as between older and younger employees, the project seeks to foster knowledge exchange, accelerate the accumulation of experience, and build research and entrepreneurial capacity.

In terms of research, the GETM3 project brings to light knowledge deficiencies via a multidisciplinary lens. From the perspective of students and younger graduates there is much to learn about career expectations including demand for the likes of flexible work arrangements, meaningful mentorship programs, and corporate purpose (Fuller, 2016). Donald and colleagues (2019) argue that student views on career trajectories and graduate employability remain poorly understood. From an employer's perspective, the World Economic Forum predicts the top skills employers will require in 2022 are analytical thinking and creativity while active learning and learning strategies are both on the rise (World Economic Forum, 2018). The future of work requires a shift in thinking to a "post-generational mindset" able to identify behaviors that unite and build strength across generations (Koulopoulos \& Keldsen, 2014). Finally, in order to navigate such changes, educators are to engage and embrace entrepreneurship by building "theoretical foundations, bridging disciplines and communities (research and practice), and increasing critical thinking perspectives" (Fayolle et al., 2016, p. 896). In order to show how these challenges were explored, it is first necessary to describe the formation of the GETM3 consortium and project.

\section{Take Your Partners! Origins of the Research Proposal}

GETM3 is the latest in a series of five highly successful overlapping international collaborations conducted over a period of 11 years across higher education and industry. During this time, a unique network of diverse personal and professional relationships developed among individuals operating in the United Kingdom, Ireland, Poland, Slovenia, and the Republic of Korea, where historically "geographical distance has been compounded by psychological distance" (Bridges, 1986, p.22). The collaboration began with a small, experimental, student mobility cooperation of seven partners. This group was funded by the Education Cooperation Programme, a part of the Industrialized Countries Instrument, an EU collaboration agreement among the EU and Australia, New Zealand, Japan and the Republic of Korea. Securing this funding started a remarkable series of increasingly complex, ambitious 
projects which received over four million euros from the European Union and the Korean Research Foundation. A pattern of sustained relationships and foundation of trust and understanding has emerged at the heart of this success. A global employability network was formed as a loose collaboration of researchers from different social sciences. Commonalities, intersections, and synergies were identified, as well as a desire to recognize and accommodate cultural differences and norms. This critical foundation of the 16-partner consortium that is GETM3.

\section{Blood, Sweat, and Tears: Successful Funding Strategy}

While working together, the partners devised a 'strategy' for funding success. They called it blood, sweat, and tears to signify the following action guidelines respectively: focus on relationships before tasks, work with passion, and let go of sacred cows. Partners were carefully selected based on past experience and trusted recommendations. Special notice was taken of passion for understanding careers, especially enabling the potential of young people. This made it possible to convey to funders a clear vision and purpose (Hollensbe et al., 2014). The early design and use of a logo in the GETM3 funding bid demonstrated this sense of vision and coherence. The group established a project-specific culture while working within the various constraints and norms of partner institutions, and remaining cognizant of funder requirements. The project team worked pragmatically across boundaries and, like entrepreneurs, piggy-backed resources (Burgelman, 1983b; Herr \& Anderson, 2005). The leadership team at the University of Northumbria in Newcastle (United Kingdom) managed the bidding process and application, strategically delegating content to subject-matter experts. The final submission was a 60 -page narrative and plan supported by a detailed four-year staff mobility plan. The motivational catalyst for GETM3 was nearing completion of an existing project and a desire to sustain invested, successful relationships. The significant workload and effort to pull the submission together reinforced the culture of collaboration and desire for achievement. The team submitted their final document one hour before the deadline. They attributed the success of their submission to practising Burgelman's (1983a) "strategic neglect": "the more or less deliberate tendency of [strategic entrepreneurs] to attend only to performance criteria on which the venture's survival is critically dependent." (p.234). The project was ambitious, and failure at first attempt was expected.

\section{Strategic Entrepreneurship: Infrastructure for Success}

Securing international funding has increasingly become a key strategy for higher education institutions. Burgelman's (1983a) theory of strategic entrepreneurship identifies autonomous strategic behavior in which "entrepreneurial participants (...) conceive new (...) opportunities (..), mobilize corporate resources for these new opportunities, and (...) create momentum for their future development" (p. 65). Individuals engaging in such behavior attempt to escape (p. 65) the presiding 
structural context. For GETM3, this meant working with peers in other faculties and institutions, rather than exclusively within respective hierarchies. Autonomous strategic behavior is "purposeful from the perspective of the actors who engage in it" (Burgelman, 1983b, p. 1350). It is conceptually equivalent to entrepreneurial activity, yet it delivers part of an existing strategy. New managerial approaches and innovative administrative arrangements are required to facilitate collaboration among participants (the strategic entrepreneurs) and their organizations.

The first year of the GETM3 project was spent establishing new policies and processes (see the vignette later in the chapter). Strategic entrepreneurs admit to being "just smart enough to hire people smarter than themselves" (Thornberry, 2001, p. 532), hence the importance of partner choice. The individual entrepreneur, or in this case the project leader, must set in motion a virtuous circle by convincing people that the innovation they want to pursue is in their own interest (Burgelman \& Hitt, 2007). It is critical to a project's success that an ecosystem of interested partners develops a collective interest around the entrepreneurial leader. The total collective benefit that results from "leveraging off the self-interest" (p. 351) of the individual entrepreneur can be substantial, even though this collective interest may not have formed part of the original idea.

\section{Engagement and 'Multisociation': Bypassing Traditional Distinctions}

The aim of GETM3 is to provide innovative research and enhanced impact by producing evidence-based, actionable, knowledge and artifacts (Argyris, 2003; Gubbins et al., 2018; Voss, 2019). According to Smith and DiGregorio (2002), "bisociation" occurs when two previously unrelated matrices of information or knowledge are combined to create novelty. The intent of GETM3 is to exceed this through "multisociation," a unique concept developed for the purpose of this project. It emerged from a plan to apply theory, concepts, and approaches from one discipline to several others. One example is applying Lean Six Sigma to every aspect of the project, including research, management, and in the production of integrated deliverables (see later in the chapter). Another is using design thinking from the design of the project through to the co-creation of project deliverables with multiple stakeholders (cf. Rouse, 2019). One example is an exercise to explore career expectations and skills required for jobs that do not yet exist (Bailey et al., 2018).

Reflecting its interdisciplinary focus, the project team avoided explicit focus on quantitative/qualitative distinctions or ideological preferences for methodologies. Constant philosophical introspection, can become a distraction (Reason \& Bradbury, 2006), while. problems in judging managerial knowledge and writing are "ingrained and remarkably counter-productive" (Pfeffer \& Sutton, 2006, p. 27).Instead, a pragmatic focus on impact resulted in an inclusive approach to knowledge and understanding. Knowledge from different sources as a form of multiple triangulation was selected for its relevance to researcher development, enhanced understanding of careers, and external impact. These fundamental assumptions in turn informed the design of the project as detailed in the next section. 


\section{RESEARCH DESIGN}

Complex mega-projects like GETM3 have distinctive characteristics which present challenges for management (Van Rijnsoever and Hessels, 2011; König et al., 2013; Anzai et al., 2012). These include: (i) outcomes that are often ill-defined, as reflecting the nature of research; (ii) the balance between maintaining a strategic focus and respecting disciplinary integrity; (iii) a diverse and temporary team of independent partners based in multiple international locations; (iv) interdisciplinary research teams drawn from disparate disciplines and methodological backgrounds; and (v) the involvement of stakeholders from multiple sectors (higher education, large companies, SMEs, NGOs, government agencies, etc.). It is acknowledged that management methodologies for complex research projects are under-developed (König et al., 2013; Anzai et al., 2012), as is management of interdisciplinary research projects in general (König et al., 2013). All this points to the imperative of putting in place key guiding principles and underlying values to inform research design, including democracy, diplomacy, impact, gender, learning objectives, and plans for dissemination.

\section{Multidisciplinary Research: Democracy through Design}

Multidisciplinary research is problematic, in part because universities remain organized in disciplinary silos that respond to and perpetuate research funding streams and academic communities of self-gratification, thereby mitigating against collaboration. (Exceptions include designated multidisciplinary research centers.) A silo approach rarely reflects the realities of practical real-world challenges. A key dilemma for the GETM3 project is that its ultimate beneficiaries, employers and graduate talent, predominantly reside within this real world. Key stakeholder concerns do not relate to theoretical advancement of knowledge within a closely guarded disciplinary domain. Instead, their concerns are how to inform careers and enhance the management of talent in business. Based on this logic, the GETM3 approach to multidisciplinary research was established around pragmatism. Two practices were adopted for the multidisciplinary research design: (a) co-creative knowledge creation and exchange events, termed sandpits; and (b) Integrated Academic Practice (IAP), an approach allowing portfolios of Research \& Innovation, Learning \& Teaching, and Knowledge Exchange to work in harmony to deliver reciprocal values that benefit the academy, students, and society (Bailey \& Smith, 2016).

The UK's Engineering and Physical Sciences Research Council (EPSRC, 2019) defines a sandpit as "intensive discussion forums where free thinking is encouraged to delve into the problems on the agenda to uncover innovative solutions." Within the design and delivery of the GETM3 project, the team adopted a creative, design-led approach that embedded quarterly sandpits within the program funding and governance. Sandpit meetings were scheduled on a quarterly basis rotating around partner institutions with sixteen taking place in four years. Sandpits allowed key protagonists to convene around the prosaic matters of project management, but each host 
institution was left to design and facilitate meetings whose purpose was to "uncover innovative solutions."

Sandpits have been hosted in a variety of ways to engage graduate talent and research employers in action research focused on delivering data that will inform the core research questions of the GETM3 program. Sandpits were built around multisociation, that is, a plan to apply theory, concepts, and approaches from one discipline to several others. The role of design thinking proved beneficial in mediating between disciplinary and practice experience and expectations (Bailey et al., 2019; Voss, 2019). Design thinking provided a structure and resources to facilitate discussion, debate, and creativity between disciplinary and experience experts within a "safe environment" (Bailey \& Smith, 2010). Because most subject expertise in GETM3 came from disciplines other than design, participants have been willing and curious to engage with a design-led approach which seeks to democratize idea ownership,

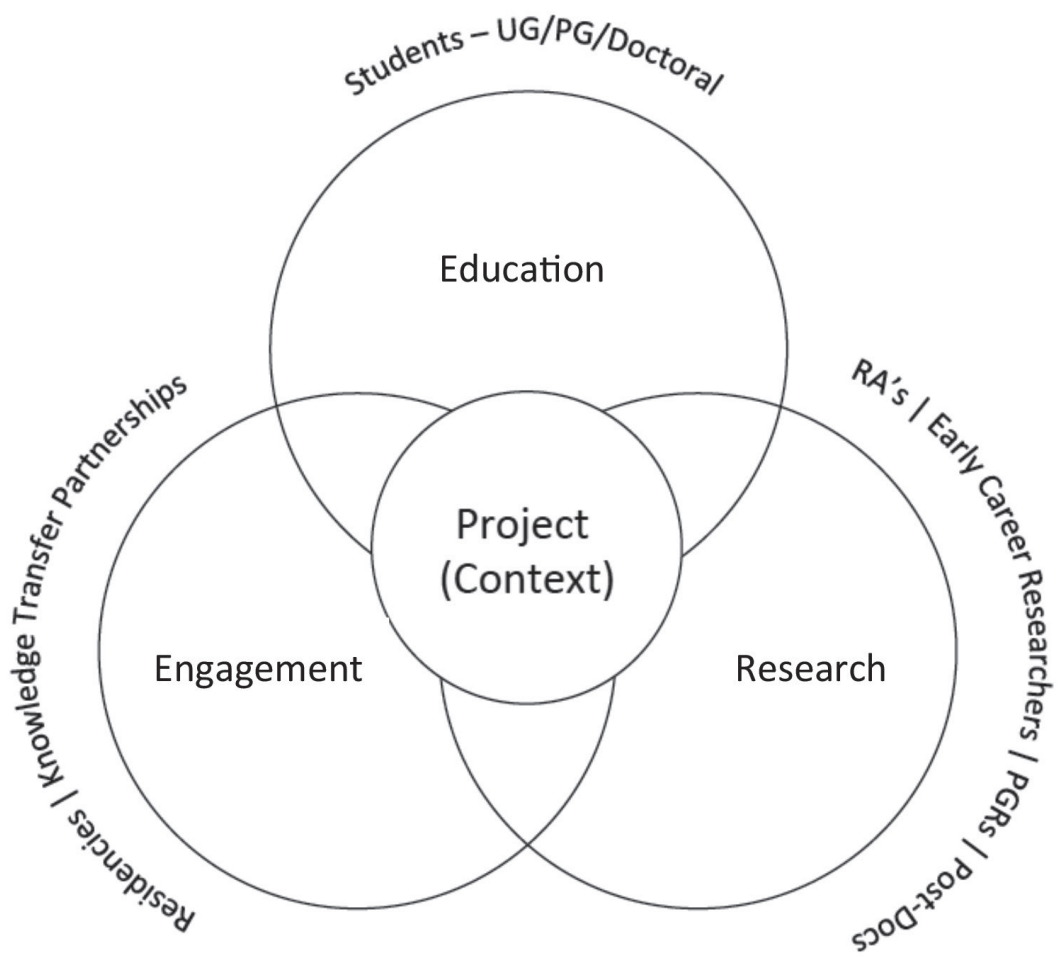

Note: $\quad$ PGR postgraduate researcher / RA research assistant / UG undergraduate.

Source: $\quad$ Bailey \& Smith (2016).

Figure 4.1 A model for integrated academic practice 
as well as to externalize and build on concepts and emerging possibilities without judgment or fear of criticism.

The same democratic approach underpins Integrated Academic Practice (IAP) employed in GETM3's engagement with students and recent graduates. In this approach participants are valued as co-researchers engaged in generative research at the front end of design (Sanders \& Stappers, 2008). Importantly, and unusually for management research, student knowledge, experience, and ideas are valued as equally relevant and informative as those of seasoned academics or industrial practitioners. As illustrated in Figure 4.1, the model employed places project-based activity at the center of inquiry.

GETM3 used the IAP approach to engage multiple groups of students and postgraduates in a series of creative workshops exploring the critical question of "how universities should prepare graduates for jobs that do not yet exist?" (Bailey et al., 2018). Illustrative of the diversity and democracy of such an approach, in one such set of workshops, the cohort comprised 17 students representing eight nationalities. Participants had studied in six different countries, and their work had focused on 12 different subjects including mathematics, fine art, journalism, software engineering, sociology, and design. They had between zero and 10 years of professional employment experience, and the workshop had close to an equal number of participants by gender.

The raw data generated by each subsequent iteration of the workshops provide researchers with an evolving understanding of the fundamental concerns of graduate talent as they approached their future careers. Researchers fed these integrated outputs into recommendations and integrated outputs of the GETM3 program. Deliverables such as an Employer Toolkit will offer practical tools to enable employers and employees to find mutually beneficial middle-ground, enabling both to flourish in an unpredictable and rapidly changing world.

\section{Designing International Research: Diplomacy and Work Packages}

The GETM3 project consists of seven 'work packages' (WPs) or workstreams (see Table 4.1).

Table 4.1 GETM3 work packages

\begin{tabular}{|c|c|c|c|c|c|c|}
\hline WP1 & WP2 & WP3 & WP4 & WP5 & WP6 & WP7 \\
\hline $\begin{array}{l}\text { Project } \\
\text { management }\end{array}$ & $\begin{array}{l}\text { Young } \\
\text { people } \\
\text { attitudes }\end{array}$ & $\begin{array}{l}\text { Higher } \\
\text { education } \\
\text { institutions }\end{array}$ & $\begin{array}{l}\text { Employer talent } \\
\text { management }\end{array}$ & $\begin{array}{l}\text { Research } \\
\text { outputs and } \\
\text { integration }\end{array}$ & $\begin{array}{l}\text { Networking, } \\
\text { dissemination, } \\
\text { communication, } \\
\text { researcher } \\
\text { development }\end{array}$ & $\begin{array}{l}\text { Research } \\
\text { ethics and } \\
\text { management }\end{array}$ \\
\hline
\end{tabular}

A detailed research design was required for the three WPs aimed at understanding stakeholder perspectives (see Table 4.2). These work packages were: WP2, focused 
Table 4.2 GETM3 research design

\begin{tabular}{|c|c|c|c|c|c|c|c|c|}
\hline WP2 & & & WP3 & & & WP4 & & \\
\hline WP2 & $\begin{array}{l}\text { Other } \\
\text { WPs }\end{array}$ & $\begin{array}{l}\text { Individual } \\
\text { research*** }\end{array}$ & WP3 & $\begin{array}{l}\text { Other } \\
\text { WPs }\end{array}$ & $\begin{array}{l}\text { Individual } \\
\text { research*** }\end{array}$ & WP4 & Other WPs & $\begin{array}{l}\text { Individual } \\
\text { research*** }\end{array}$ \\
\hline $\begin{array}{l}\text { Student and } \\
\text { graduate } \\
\text { development* } \\
\text { (major research } \\
\text { stream) }\end{array}$ & $\begin{array}{l}\text { WP } \\
3 \& 4 * *\end{array}$ & $\begin{array}{l}\text { Research } \\
\text { within the } \\
\text { scope of } \\
\text { GETM3 }\end{array}$ & $\begin{array}{l}\text { Researching } \\
\text { higher } \\
\text { education* } \\
\text { (major } \\
\text { research } \\
\text { stream) }\end{array}$ & $\begin{array}{l}\text { WP } \\
2 \& 4 * *\end{array}$ & $\begin{array}{l}\text { Research } \\
\text { within the } \\
\text { scope of } \\
\text { GETM3 }\end{array}$ & $\begin{array}{l}\text { Employer } \\
\text { global talent } \\
\text { management } \\
\text { challenges* } \\
\text { (major } \\
\text { research } \\
\text { stream) }\end{array}$ & $\begin{array}{l}\text { WP } \\
2 \& 3 * *\end{array}$ & $\begin{array}{l}\text { Research } \\
\text { within the } \\
\text { scope of } \\
\text { GETM3 }\end{array}$ \\
\hline
\end{tabular}

Notes:

Integration across the following issues: generations, stakeholders, countries, disciplines, sectors, gender, WPs.

*main module (major research stream) addresses research objectives from the grant proposal.

**modules with additional questions/statements from other WPs in order to achieve triangulation of perspectives.

***every secondee/participant may submit individual research proposal within the scope of GETM3 (to be approved by WP leaders).

on student and graduate development and led by the University of Warsaw; WP3, focused on researching higher education and led by Dublin City University; and WP4, focused on resolving challenges to employers in global talent management, led by the University of Ljubljana. The research design for each WP was based on three key components, as follows:

1. The objectives of each WP was stated in the bid and grant agreement. WP leaders were responsible for preparing the research module that included a description of a sample, a method (e.g., such as a survey), tools (e.g., a questionnaire), and the type of study (e.g., cross-sectional).

2. Integration of perspectives. In order to achieve triangulation of perspectives, it was possible to add modules, emerging from other WPs to the main research stream of a particular WP. For example, WP1 could prepare a module addressing gender issues which are included in WP4.

3. Individual researcher interests. Over 100 participants were involved in GETM3, representing many interests, skills, and backgrounds (from engineers, to designers, and researchers, to technical personnel). The research design reflected this diversity in two ways:

a. Each participant or research secondee was required to contribute to overall project objectives. Depending on their interests, they could discuss their tasks with the relevant WP leader. Assigned tasks could vary from desk research to data collection and analysis.

b. Each participant could propose their own research project to conduct with the cooperation of other project participants. Such proposals were considered and approved by relevant WP leaders. This enabled deeper understand- 
ing of global entrepreneurial talent management issues from a variety of perspectives, while balancing the achievement of both project deliverables and individual research interests.

In order to achieve a required level of understanding and cooperation among WP leaders, various forms of communication were used. Crucial agreements were made during face-to-face discussions that took place during the sandpit events detailed above. All WPs feed into an integration work package, WP5 led by the Technological University Dublin, which received state-of-the-art evidence from four key areas: (i) integrating interdisciplinary research, (ii) integrating multiple sectors, (iii) integrating diverse stakeholders, and (iv) integrating international research teams. The research design was also informed by the publication strategy and designed to meet EU and institutional requirements as well as facilitate meeting project objectives (i.e., international networking and collaboration). Flexibility was key to addressing new issues and questions that came up as the project moved forward and as new participants joined the initiative.

\section{Reflecting Gender in Multicultural Research}

Previous research exploring the theme of entrepreneurship has been criticized as being "about men, by men, and for men" (Holquist \& Sundin, 1991, p. 1). GETM3 was committed to: (a) promote and ensure gender consciousness and equality throughout the management and research process, and through the participation of GETM3 stakeholders; and (b) embed gender as a key focal dimension in the research and work packages, consistent with Horizon 2020 gender equality guidelines (European Commission, 2019). In doing so, the GETM3 project recognized the critical role of gender for research excellence, in adding value quality and creativity in outcomes, in greater responsiveness to social needs, and in producing goods, technology, and services suited to potential markets (European Commission, 2019; Stanford University, 2019).

To address gender in project management and networking, a gender champion was appointed to monitor all gender aspects on both WP1 and the project steering committee (PSC) at the start of the project. WP leader and researcher roles were allocated as evenly as possible, with females somewhat more represented. Gender mainstreaming was a standing theme on the PSC agenda and for the sandpits, with gender being considered and recorded in a project log on the project portal by each GETM3 project partner at planning, implementation, and evaluation stages. A GETM3 Gender Policy was formulated by the gender champion as a key deliverable of WP1. This process was supported by an adapted Five-Step Gender Proofing Process template (Crawley \& O'Meara, 2002) which set forth five points to address and incorporate into organization strategy: (i) different needs and experiences; (ii) related implications for the activity; (iii) how to ensure equal participation and outcomes for the sexes; (iv) a person responsible for implementation; and (v) how to measure success of the activity. In addition, a process known as "member checking" allowed 
a project member to challenge another's gender consciousness. The collection of participant bio data further supported gender mainstreaming. The WP leaders and steering committee were critical throughout this process. They encouraged sharing and dissemination of best practices and lessons learned, within and across WPs, and also identified potential amendments to the gender policy, which was considered a working document and subject to change. They also pro-actively addressed equal participation in research secondments. Men outnumbered women at the start of the project, so leaders examined reasons for the gender imbalance and designed steps to overcome it, using open dialogue around family commitments and how best to provide support.

To address the gender in research content, gender was incorporated across all WPs as a key focal variable in research design, analysis, findings, and practical recommendations. GETM3 was very conscious of the gendered framing of entrepreneur identities and related activities portrayed in both academic and practitioner literature (Ahl \& Marlow, 2012; Marlow \& Martinez Dy, 2018). By including project deliverables such as a White Paper on transcending gender, and a GETM3 gender policy in the Horizon 2020 funding application, the project team clearly demonstrated their commitment to gender as a key priority and held themselves accountable. These are two critical success factors for gender equality initiatives (Kossek et al., 2006; Fortune \& SHRM, 2001).

\section{Out of the Ivory Tower: Ensuring Research Impact}

Research impact is critical not only to employer stakeholders, but increasingly also to the careers of academics. The debate around the research vs. practice divide in management studies is not new. Nonetheless, academic career trajectories continue to be determined primarily by publications in highly ranked journals (DeNisi et al., 2014). There is a sense of gradual shift in policy, away from impact in academia measured purely by citations, toward a more holistic assessment (Aguinis et al., 2019). For example, the UK Research Excellence Framework (UKREF), in which the research quality of UK universities is assessed every seven years, is placing increasing emphasis on research impact; and various attempts are being made to bridge the research vs. practice divide. The evidence-based management movement (Briner, 1998; Rousseau, 2012) has gained traction, as have initiatives to make management research useful for practitioners (Tkachenko et al., 2016; Bansal et al., 2012). Leading academics in different countries are addressing this concern, including with respect to entrepreneurship (Wiklund et al., 2019). However, a problem with evidence-based management is that it tends to focus on how to impact or disseminate findings after research has been completed, a kind of post hoc engineering. Addressing such deficiencies, GETM3 has taken a rigorous approach to achieving impact by engaging with potential beneficiaries of the research at every step of the process.

Notably at the outset, the GETM3 project appointed an Impact Champion tasked with writing the funding bid and ensuring that those working on the project understand what impact means in the context of GETM3. Achieving impact was made an 
integral part of the research design by adopting the impact management framework developed by Reed (2016) in Figure 4.2. The inclusion of a UKREF exemplary case study as a contracted output ensured impact as a priority. Impact reinforcement became an ongoing part of quarterly sandpit meetings, which were used for impact training around analysis of research motivations, stakeholder analysis, and likely impacts.

\section{Publics and Stakeholder Analysis Template}

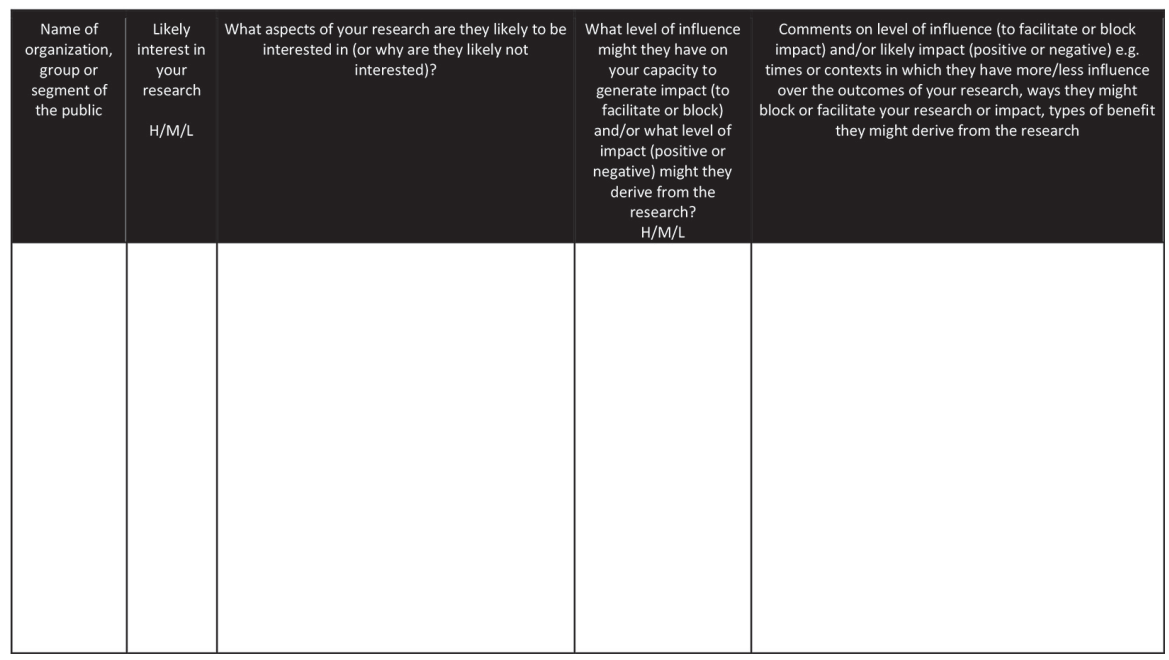

Figure 4.2 Stakeholder and public analysis template

For motivation, researchers considered how to make the world a better place by helping people make better decisions, by improving well-being, teaching and learning, and by reducing staff turnover or helping small companies compete for talent. Impact was evaluated in terms of: significance, as judged by the degree to which it influences policies, practices, products or perceptions; and reach, as determined by the extent of impact and the diversity of those impacted. Stakeholders were listed, wants and needs identified, assumptions challenged, and means of capturing feedback considered.

Early and significant benefits accrued as a result of the emphasis on impact. These include enhanced cohesion among WPs through the common theme of impact, illuminating crossover between stakeholders. Results were presented to stakeholders and dissemination events organized with employer groups. Employers were consulted about the tools being developed and about the potential drafting of several potential UKREF impact case studies. Arguably, the greatest benefit has been developing 
an impact mindset which has informed project research decisions and early career researchers who will take this approach into their futures.

\section{Capturing the Learning: the Never-Ending Journey}

Career development is integral to societal, educational, and performance measures for which academics and their universities are increasingly held accountable (Zacher et al., 2019). Providing evidence of research capacity development on an individual and collective basis is a key requirement of EU funding for GETM3. An interdisciplinary team skilled in learning and innovation processes undertook design and delivery of a learning system. This involved procedures and tools to support and provide evidence for ongoing and final reports to key stakeholders, including funders, host organizations, and project participants.

The primary means to enhance career development was participation in the international secondment opportunities. This required a system to facilitate and capture the learning from these experiences. The project team therefore designed the following instruments:

1. Learning Platform - a dynamic online collaborative learning environment, which provides access to a repository of learning and research resources and outputs from ongoing research activity within the project.

2. Personal/Professional Development Matrix - all secondees receive a subscription to the VITAE researcher development website (https:/www.vitae.ac.uk/) to access learning resources to support their professional development. The Vitae Researcher Development Framework (RDF) outlines characteristics of excellent researchers and provides a structure to inform, develop, and record learning gained by individual members. All project members perform a self-assessment using the Vitae RDF at the beginning and end of the project, to inform a quantitative and qualitative analysis of researcher development.

3. Individual Research Development Learning Record (IRDLR) - an online tool developed using MoveON mobility software. Participants complete an individual development plan, creating a reflective record of their individual learning journey before, during, and after their secondment. Motivating secondees to record their learning can be challenging. Therefore, workshops are included in the sandpit events, and country team leaders are tasked with ensuring their own secondees' submissions.

Initial analysis of a sample of completed IRDLRs conducted mid-way through the project indicated opportunities which did enhance career development. International secondments increased participant confidence and competence in developing their networks, familiarizing with foreign cultures, expanding their research horizons by activities such as delivering research seminars in host institutions, and opening new collaborations with international partners. 
There is clear evidence that participation in the project has elicited a reflective approach to understanding and reimagining secondees' own careers. Many took the opportunity to develop new professional skills beyond research, and to transfer learning back to their own institutions. For some, this contributed to achieving a promotion or identification of other opportunities which previously did not exist. Overall, there is early strong evidence of increased confidence in cross-cultural communication and in forming new working relationships. As suggested throughout this chapter, the quarterly sandpits are critical in building social capital to sustain these new long-distance relationships, and this has been reflected in the addition of a new, informal work package dedicated purely to activities building social capital. All of these interactions are institutionally and culturally patterned, and as one participant commented, "there is no way to read that in a book."

\section{Innovative Dissemination and Communication for Diverse Audiences}

A final core aspect of research design involves strategies for communication and dissemination. GETM3 is an international, virtual project where team members are "dispersed geographically and working in different organisations" (Binder, 2016 p.1). This means running a virtual team with the additional challenges of geo-location, language, power-distance, culture, and technology preferences (Neeley, 2015). With over 100 participants across 16 universities, companies in five different countries, three major stakeholder groups, and a powerful funder, success of the project depends on communicating and disseminating information to multiple stakeholders.

An open culture of information-sharing and communication is required to ensure that appropriate, timely and engaging information is available to all stakeholders. This culture aids management effectiveness and overall group task performance in virtual teams (Warkentin \& Beranek, 1999). Communication failure could isolate key contributors and reduce project effectiveness (Leenders et al., 2003). A multi-factor communication approach was taken, targeting stakeholders as follows: internal project stakeholder (active members in management, administration, and research mobilities); funding and institution stakeholders (the European Commission, the Korean Research Foundation, and organizations where members work); stakeholder targets for dissemination (project research output went to three groups: higher education institutions, students/young graduates, and businesses).

Different stakeholders required information at various times and in varying formats for communication to be effective. A single communication strategy would fail to meet demands of all identified stakeholders. The following three principles were considered paramount: information timeliness, format appropriateness, and effectiveness of the communication approach.

For internal project stakeholders, a centralized repository acted as a project management tool, mobility secondment tracker, project archive, confidential data repository, and a collaborative space where the team could share and edit online single-source documents. This eliminated any need for privately held, conflicting 
information from multiple contributors, and it allowed collaboration for participants across different time zones.

Social media are used to provide updates from participants currently on a secondment, keeping the project vibrant for those not currently active or seconded themselves. Private groups on Facebook and WhatsApp allow multimedia sharing across the project team without involving other non-research stakeholders. More traditional communication is used for funding and institutional stakeholders: a website for official updates, public Facebook and LinkedIn pages for information dissemination, and reports/presentations for project deliverables. Dissemination-targeted stakeholders are presented with a multimedia-rich, multi-tiered, web portal which gives information in varying formats and levels of detail using keywords and multiple paths. A top-down approach is used with interactive PDF documents linking to multimedia outputs interlinked through a series of keywords. These keywords allow material to be navigated using a stakeholder, pedagogical, or functional point of view. Output is also multi-tiered with headline information linking to more detailed summary video material, and eventually to a full seminar delivery of the research. Academic papers further support the seminar information providing a more rigorous academic backbone.

This innovative, stakeholder-centered approach uses readily available technology for communication. Stakeholders can access accurate, up-to-date, material tailored to their needs and in a format which suits them. Finally, with the use of private group, social-media applications, constant posting and updating on activities helps keep the project in the minds of team members, ensuring momentum throughout the project lifetime.

\section{PROJECT IMPLEMENTATION}

"Vision without execution is just hallucination" is a truism attributed to everyone from Edison to Einstein and even back to an ancient Japanese proverb. "Strategy without tactics is the slowest route to victory," said Sun Tzu, legendary Chinese military strategist. Call it execution or tactics, without implementation any project is worthless. Implementation has been referred to as grunt work (as opposed to cerebral strategizing), but we can attest to the fact that making it happen is so much more difficult than thinking it up in the first place. Our funder knows this too, and so included a significant section on implementation in the mandatory bid structure. In this section, we describe principles for and experiences in managing the project to ensure efficient and effective implementation, in light of the complexity of doing research on an international scale, on budget, on time, and meeting all contracted deliverables.

\section{Plan, Do, Check, Act: Quality Management in Research}

Multidisciplinary expertise has been core to GETM3 project success, especially with respect to quality management. Lean Six Sigma ensures efficient, effective, 
project delivery on schedule and on budget, to the satisfaction of external funders. From the initial bid stage, the team emphasized controlling and managing quality as essential to minimize the risk of disruption and failure. Total Quality Management (TQM) philosophy was used for this purpose, as well as for continuous performance improvement and to encourage stakeholder involvement (Jimenez-Jimenez et al., 2015). Project success is based on core TQM principles such as teamwork, stakeholder satisfaction, continuous improvement, transparency, and full engagement with all involved. In order to promote a TQM culture, the Plan, Do, Check, Act (PDCA) model was used during the project life cycle. This cycle, also known as the quality loop, is a model widely deployed for continuous problem solving and optimization. It was therefore considered suitable for quality management in this complicated, multidisciplinary, multi-sectoral, international project (Guo et al., 2018). It was used at the strategic level for the management team and WP leads to review progress at the mid-point evaluation, and at the operational level for each activity requiring output review, such as a secondment. Figure 4.3 illustrates how PDCA was applied. At both levels, PDCA helped prevent disruption and eliminate risk.

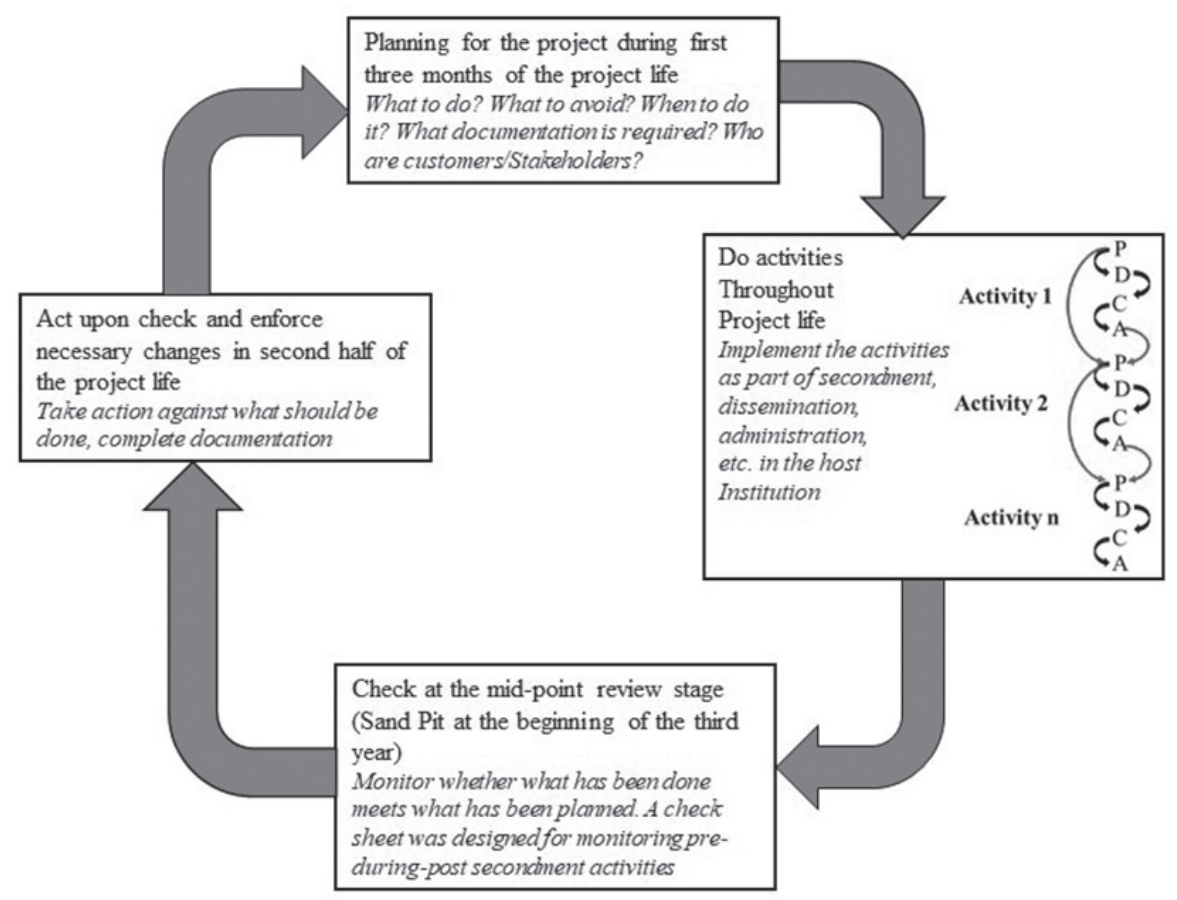

Figure 4.3 PDCA model for the GETM3 project 
At the operational level, each secondee is asked to work through a checklist of items before, during, and after their secondment, to ensure their activities follow EU guidelines. Secondment experiences are shared verbally and documented on the learning platform. PDCA is also used at sandpit events to inform possible future changes in project planning and management.

\section{Herding Cats: Reflections on Introducing and Managing Key Processes}

In the realm of university research the focus is often purely on the academic, neglecting project and administrative staff (Harney et al., 2014). A key benefit of the GETM3 project is that it aims to develop inclusion of managers, administrators, and technicians through international exchanges and mobilities. Sandpit events bring all constituents together. while in terms of governance the project steering committee and advisory board similarly have diversity of representation. The reflective vignette below captures the practical experience and challenges for a project coordinator from the co-ordinating institution.

\section{Reflection Vignette}

"I know someone who needs your experience." That is how it started: a colleague with whom I had worked in the past put me in touch with the Project Leader for GETM3 at Northumbria University. The project had already been running for a year, and there were specific and immediate challenges I needed to resolve within the first few weeks of taking on the role of Project Manager. Using my previous experience and knowledge, I created new online communication processes and monitoring procedures for the project to address these issues. Within three weeks of starting work, I travelled to a quarterly project meeting in Slovenia to present them to the wider Project Team. But then to persuade them to use them!

Up until this point, I had met only project team members from my own institution. Most others had known each other, professionally and personally for a number of years. I was the outsider, the unknown, the "administrator" in a room of academics and researchers. I had to present my ideas, new systems and processes framed by EU regulation and policy. "Northumbria are making things up," "I can't ask my colleagues to share their data with everyone in the project." "Another process!?" The reaction was disappointing but not unexpected - the group had not had time to get to know me, my background, expertise and knowledge. With the opportunity to interact with colleagues both inside and outside of a formal work setting - and by offering to help them, I built rapport, demonstrated my professional expertise, and began to establish myself as one of the team. However, once back in our respective institutions, it was still difficult to get buy-in from all participants.

Approaching the halfway point, the Mid-Term Evaluation Meeting for the project took place in Warsaw where, after a day-long Sunday rehearsal, progress to date was presented to the project advisor from the EU Commission's Research Executive Agency. 
During the event, colleagues praised the contribution I was making, and after presenting my online management system to the EU Adviser, I was directly complimented for my presentation and work which were highlighted as "exemplary." This event significantly increased my influence, authority, and reputation in the wider project team. It was a turning point: I had sufficiently built up the social capital needed to establish rapport with, and respect and engagement from, my new colleagues. As people got to know me and started to engage in the systems I had introduced, there was faster buy-in for further process improvements and implementation. However, I also recognize that my personal leadership style and ability to work across cultures have allowed me to create and maintain project team cohesion and keep the "cats" within project regulation boundaries. Ultimately, this will enhance our success.

\section{Turning Risks into Opportunities}

The wide geographic reach of international projects means that constantly fluctuating geo-political risks can have a direct bearing on planned activities. Project-specific risks can also impact activities, timetables, travel, and relationships (Richardson \& Zikic, 2007). Allocating responsibility to a dedicated risk officer, coupled with continuous risk assessment, were critical to obtaining GETM3 funding. In the context of GETM3 (which is co-ordinated in the UK and involves South Korea) the ebb and flow of recent tensions between USA and North Korea, coupled with extended swells of Brexit uncertainties, present ongoing risks that could have critically impacted the project's fundamental landscape and direction of travel. More recently the coronavirus outbreak has mandated scenario planning and ongoing consultation with institutional and national travel advisories. Other external factors such as match funding for project expansion remained uncertain in the project's early stages. Similarly, critical incidents such as the unexpected loss of key staff and partner withdrawal could have threatened the achievement of contracted project deliverables. Instead, through careful management and the maintenance of open communication and positive networks, these events actually led to project expansion and new engagements. The indirect impact of internal and external risks created personal uncertainties, leading to delays in decision-making (e.g., attracting secondees), as individuals assessed their own personal risk for threats and opportunities ahead. Personal risk assessment can be further complicated by differing individual perceptions of risk, and by risk appetite across the range of project partners around the globe. The challenge is to turn these threats into opportunities. Such a journey may result in outcomes different from those originally planned, but in so doing may serve to strengthen partner relationships, skills and openness which can benefit the project - and future projects - overall. Successful risk management for international research projects requires entrepreneurial skills also needed in other parts of a project: horizon scanning, agility, commitment, flexibility, creative thinking, and resilience under pressure. 


\section{Transnational Work: Creating Value through Managing Mobility}

"Higher education was always more internationally open than most sectors" (p. 3), and "faculty mobility has long been a positive professional norm" (p. 64) (Marginson $\&$ van der Wende, 2007). A global survey conducted by the International Association of University (IAU, 2010) revealed that $87 \%$ of universities in 115 countries included internationalization as one of their strategic goals.

Career management competence through transnational mobility may impact well-being, worker job attainment, and long-term career success (Churchman \& King, 2009). Many academic staff have experienced transnational cooperation between international institutions (Pearce \& Quan, 2015), either individually or collectively, as in the GETM3 project. Studies show that managing worker mobility is increasingly becoming a global concern. Working in a foreign country brings many challenges: linguistic, culturally, and professional. Workers must adjust to these differences (Markee, 1997). Language difficulty is an obvious challenge which affects performance (Biggs, 1998; Quan et al., 2013). There may be negative aspects of exposure to another culture, due to a lack of social support, or value differences between home and host countries. Adaptation to cultural change is stressful (Taha \& Cox, 2016). Transnational work requires cross-cultural awareness, understanding of changes in cultural identity, building self-esteem, and willingness to acquire knowledge of a new culture (Lea \& Stierer, 2011).

Dziewanowska, Quan, and Pearce (2018) analyzed the experience of GETM3 secondees. Despite similar opportunities given to all, secondees experienced different results and had varied levels of success in creating value for themselves and their organizations, as well as in responding to project objectives. This is in line with valuecreation literature which states that value is a subjective, relative, preferential, interactive, higher, abstract construct of a cognitive and affective nature (Sánchez-Fernández \& Iniesta-Bonillo, 2006). The valuecreation process is affected by personal circumstances, personality, previous experience, needs, and expectations. The presence of other people - hosts and fellow secondees - can enable or inhibit valuecreation. The process is ongoing and continues long after a particular secondment ends. Revisiting experiences and reflecting upon them has proven to result in obtaining more value. However, the assumption is that all international experiences are automatically positive. The subjectivity and variability of the experience makes it less manageable by organizations and more reliant on the selection of individuals, with previous performance clearly indicative of future effectiveness. This is an important consideration for international career development. Failure to create value from an international secondment has resulted from secondee overestimation of their abilities and proclivities, or under-estimation of the challenge, before departure. Poor engagement with a host, and a focus on maintaining contact with a home institution while away, can undermine effectiveness. Some have failed to prioritize relationship over task due to undervaluation of the importance (and difficulty) of building social capital. The GETM3 project revolves around minimum 30-day secondment periods which drive the funding model. These have been significantly more effective when 
split or combined for multiple visits, making them more flexible and feasible, and allowing early familiarization to translate into operational effectiveness later. An initial value-creation strategy to involve as many secondees as possible by recruiting a different person for each secondment soon changed into an approach of allocating multiple secondments to trusted and effective participants. Potential for success is enhanced if both individuals and organizations are open to failure, and if there is a TQM process guiding the experience for everyone.

\section{Trans-sectoral Work: Bringing Industry and Academia Together}

At the core of GETM3 are trans-sectoral partnerships between industry and academia. They offer different knowledge-sharing opportunities in terms of technology and know-how (De Wit-de Vries et al., 2018). In the design of GETM3, such opportunities are not one-off "transactional" occurrences but are embedded in the quarterly sandpit meetings, project outputs, and international mobility plans. Funder regulations stipulate that intra-European mobility secondments must be trans-sectoral, that universities must send staff to industry and vice versa. This produces a win-win situation for both stakeholder groups. Industry can obtain knowledge and learn best practices garnered from state-of-the-art research, and find ways to build competitive advantage (Partha \& David, 1994). Scholars can obtain insight on pressing industry challenges and identify new research needs (D’Este \& Perkmann, 2011) from contemporary real-life industry situations. This provides an opportunity for demand-driven, engaged scholarship as opposed to supply driven research, thereby maximizing impact. Such partnerships represent a way to coordinate innovation communities beyond organizational boundaries (Mascarenhas et al., 2018). In the Republic of Korea, transferring between academic and industry is a common career path.

When researchers and practitioners nurture collaboration across sectors in management, they contribute to reducing the science-practice gap (Banks et al., 2016). Over a period of four or five years, GETM3 offers the potential for participants to build permanent bonds rather than temporary acquaintance. Participating industry organizations include long-standing strategic partners of the universities as well as new partners. Deliberately chosen to provide the broadest possible business representation, they range from international manufacturers to SME support entities to micro start-ups across all five countries. They provide a rich context for in-depth research on careers.

Based on a reflection of GETM3 experience, the following key factors have been identified as critical to an engaging and thriving academic-industry partnership:

1. Prior relationship and building a solid trust base. Existing industry-academia cooperation (e.g., previous shorter projects, participation of employees in the university's education programs) can be successfully extended in joint research projects. Trust between stakeholders is developed through building social capital which facilitates greater cooperation (Mascarenhas et al., 2018) and this goal has been built into the sandpit events. 
2. Designated partner liaison. GETM3 borrowed the role of key account manager from industry: local, named individuals in each university were appointed from the start to serve as liaison with industry partners and represent their interests. This protected the business from unreasonable demands and assured their benefit, thereby preserving the local partnership. In most cases, this role is mirrored in the businesses. The management of public money requires a bureaucracy for accountability.

3. Regular communication. Good, pro-active communication is essential (De Wit-de Vries et al., 2018) and takes various forms according to those involved. It is facilitated by key account managers, who control the communication channel as required. Face-to-face involvement is supported by budgeting for travel to international meetings. Technology use is widespread, ensuring project task fulfillment and participation by academic leads.

4. Flexibility. Universities are large diversified organizations with multiple stakeholders which can render decision-making slow and complex. A publicly funded research project entails bureaucracy, continuous reporting, and periodic evaluation by a remote body. These aspects are different from how commercial organizations run, so flexibility is required by project managers. Industry experience in academia can make this easier.

5. Opportunity for primary research. Industry partners open doors to researchers and enable primary data collection for qualitative and quantitative research. Gathering data needs to comply with the highest ethical research standards and may also involve non-disclosure agreements. For this purpose, a project coordinator in the company identifies relevant audiences and connects them with the researchers. Industry partners generously open their doors to researchers during sandpit events, which brings practitioners and researchers together.

The activities above take time and require personal engagement from corporate and higher education partners, which can increase workloads and resource needs. Early recognition of the importance of these activities contributes to project success.

\section{Advancing Understanding through Innovative Methodologies}

The success of international mega-projects usually depends on intensity, quality, and participant interaction. Such projects offer learning and development through relational exchange. GETM3 was engineered to facilitate individual and institutional development by enriching their developmental networks (Dobrow et al., 2012) and providing opportunities for career insights.

The project introduced three innovative design features that provide individual development through interaction. Sandpits require physical co-location of project participants and are organized to allow for ample social interaction and relational exchange. A mobility plan of simultaneous secondments creates time periods when two participants are on secondment at the same location and time. By rule of physical proximity and the same hosts, these secondments allow researchers to meet and 
interact and engage in relational exchange (Contractor et al., 2006). Rotation around five countries ensures repeated interaction even with individuals who cannot travel. Further, secondees are placed so that professors work with less experienced researchers, and they learn from one another.

These innovative design features and their potential to affect personal and professional development through relational exchange can be addressed with particular types of social network analysis not often used in career research - two-mode network analysis and co-occurrence analysis (Borgatti et al., 2018; De Nooy et al., 2018). A particular strength of the project is longitudinal application as the sandpits and secondments unfold over time. In essence, a two-mode network analysis examines two different sets of actors (i.e., individuals and events) and relations between them. GETM3's two-mode network features a first type of node (individual project participant), a second type of node (a sandpit or a secondment at a particular time-location point), and relations between them. For example, participant $\mathrm{X}$ was on a secondment in place $\mathrm{X}$ on date $\mathrm{Y}$, or participant $\mathrm{X}$ was present at the sandpit $\mathrm{Z}$. This two-mode network can be transformed into a one-mode co-occurrence network, with only project participants as actors and co-occurrences at events as ties. For example, if two participants participated at three of the same sandpits, they have a higher co-occurrence score than two participants who participated at three separate sandpits (zero co-occurrences). The likelihood of interaction and relational exchange is much higher in the former. Co-occurrence networks can be further analyzed with specialized methods (see De Nooy et al., 2018), while co-occurrence scores can serve as input for other types of analyses such as regression.

It is valuable to use co-occurrences as potential for enhancing relational networks and opportunities for experiential insights. Relating them to actual individual professional and personal development - also at an institutional and international level - at project closure will contribute to its overall evaluation. Data collection and analysis can continue beyond. This represents a new approach to examining how large, mobility-based, international projects can affect the career development of project participants, with implications for project design and funding decisions.

Another form of methodological innovation, bibliometric methods, uses citations as the basis for evaluating the impact of a particular document. It enables researchers interested in reviewing a specific field to obtain an objective overview of the area (Zupic \& Čater, 2015). Two types of bibliometric analysis have been used: document co-citation, which explores relationships and interactions between different researchers, revealing the intellectual traditions within a field (Vogel, 2012); and bibliographic coupling, which enables the identification of emergent topics (Van Raan, 2005). These approaches enabled the team to create a network-graphic representation of the intellectual structure, and of the scientific communication of research on entrepreneurial talent management and its various sub-domains, identifying the core theories used to inform the field and the current state of the art.

The words entrepreneurial (or entrepreneurship) and talent management were selected as keywords for search in the Web of Science Core Collection, resulting in 55 primary articles directly related to the topic (see Figure 4.4). ${ }^{1}$ Most are journal 


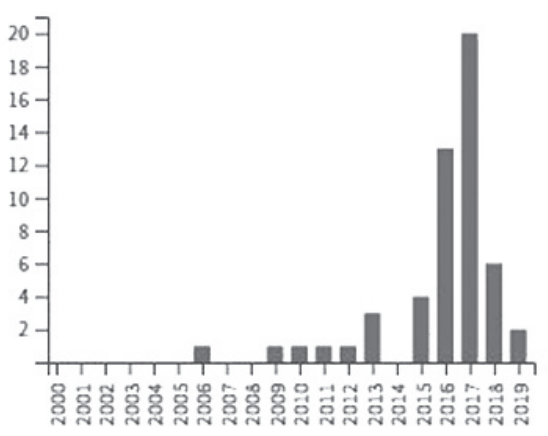

Total publications by year

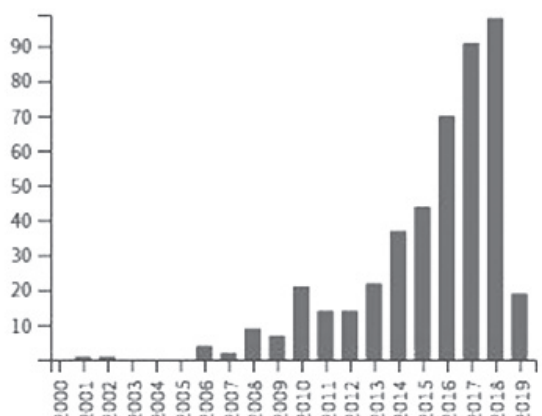

Times cited per year

Source: Web of Science Core Collection 2019, https://clarivate.com/webofsciencegroup/solutions/web -of-science-core-collection/.

\section{Figure 4.4 Bibliometric data of primary articles}

articles in the fields of either entrepreneurship or human resource management, and most were published in the last decade, clearly indicating an increase in the popularity of such overlap in areas studied.

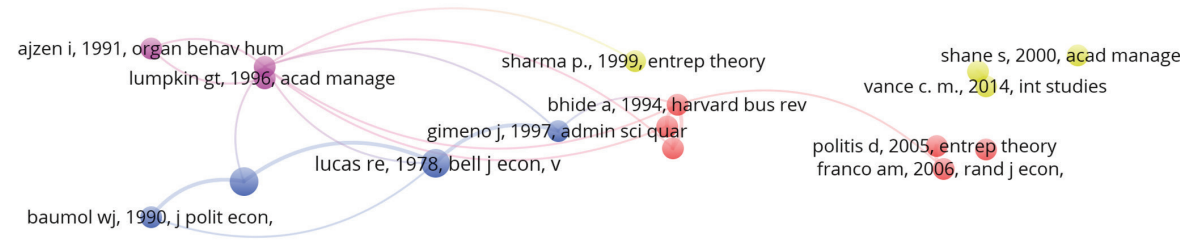

Source: The authors.

\section{Figure 4.5 Co-citation results visualization}

The networks portraying key documents, thematic clusters, and their connections were then visualized using the VosViewer software. ${ }^{2}$ Co-citation analysis results, focused on the foundations of the field overlapping between entrepreneurship and talent management, revealed four clusters (see Figure 4.5). The first (pink) is about entrepreneurial orientation and the theory of planned behavior. The second (blue) takes an economics perspective on entrepreneurship. The third (yellow) displays the foundation of entrepreneurship theory, and the fourth (red) involves the interplay 
between entrepreneurship and management (touching upon topics such as strategy, knowledge diffusion, and learning).

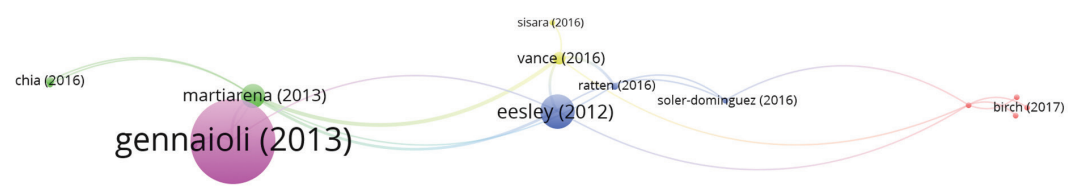

Source: The authors.

Figure 4.6 Bibliographic coupling results visualization

Bibliographic coupling results, concentrated on current trends and hot topics in the field, identified four clusters (Figure 4.6). The most impactful (pink) revolves around finance and risk assessment. The second (blue) is about talent, entrepreneurial performance, and investments. The third (green) is about intrapreneurship and the fourth (yellow) about the cultural background predictors of success.

Taken together, these analyses demonstrate the potential to enhance the understanding of the connection between entrepreneurialism and talent management. Connections to finance, strategic entrepreneurship (Burgelman, 1983a), and personal-cultural antecedents clearly represent viable options for further research on how to manage one's career as an entrepreneurial person, which will inform younger people entering the workforce today and in the future.

\section{Career Implications of Working in International Project for PhD Students}

GETM3 provides instrumental career development for early-stage researchers in the form of (a) tangible and intangible resources and (b) networking through trans-sectoral, transgenerational, and transnational exchange, thus improving professional, transferable, and personal skills of researchers. First, GETM3's unique international mobility opportunities develop early-stage, professional, research skills in a cross-cultural and inclusive environment. For example, embedded in secondment experiences, researchers apply various qualitative and quantitative research methods such as interviews, focus groups, action research, and surveys, in collaboration with experienced experts.

Second, GETM3 promotes the development of transferable skills through a variety of formats. This includes cooperating and communicating in multicultural teams and practicing presentation skills by disseminating research outputs at international conferences. Stimulating intellectual exchange across 16 organizations in five countries, the project also nurtures essential skills such as adaptability, cultural integration, networking, and leadership. 
Since the development of professional, transferable skills is significant, GETM3 enhances the personal development of early-stage researchers. Confidence and a sense of belonging were built by active engagement in project activities and international interactions that followed. The project encouraged early-stage researchers to tap into a worldwide network of academics and business partners. Professional, personal, and emotional support was forthcoming, and this can be especially valuable for PhD students. For instance, the personal network of GETM3 participants evolved exponentially, enabling a community of practice for knowledge-sharing among global project partners in the private and academic sectors. Enthusiasm for collaboration shown at all levels helped junior scholars develop social capital at the outset of their careers.

In conclusion, GETM3's inclusive project culture not only advanced various professional skills but also enriched the life experience of the early-stage researchers involved. International collaboration such as this has a multitude of positive implications for the employability of $\mathrm{PhD}$ students and their career development.

\section{CONCLUSION}

The purpose of this chapter has been to outline the benefits and challenges of a mega-project exploring the entrepreneurial nature of careers. It would be false to suggest everything has progressed in the linear and rational way initially intended. Indeed, the strategically entrepreneurial way in which the management team and most participants respond to opportunities and difficulties is part of overall project success. There is little doubt that the systematic identification of key issues identified in the underpinning, design, methodology, and implementation helped navigate challenges, and has also enhanced project impact. Although at the time of this summary, the GETM3 project is only three years through four years of implementation, it has already achieved the dual benefit of researching entrepreneurial careers as well as building and enhancing entrepreneurial career capacity.

\section{ACKNOWLEDGMENTS}

The Global Entrepreneurial Talent Management 3 (GETM3) project receives funding from the European Union's Horizon 2020 research and innovation program under Marie Skłodowska-Curie grant agreement No 734824. This chapter was written by academic, industry and managerial members of the GETM3 team at Northumbria University and Highfly Ventures Ltd. (UK), Dublin City University and Technological University Dublin (Ireland), Warsaw University (Poland), Ljubljana University (Slovenia), and Chonnam National University and Megagen (S. Korea). It was enabled by the GETM3 Overview session presented as part of the Dublin sandpit/ HR Division International Conference, January 2019, at Dublin City University, Ireland. 


\section{NOTES}

1. As of July 1, 2019, Google Scholar showed 18 indexed documents that specifically mention GETM3, all authored by project participants.

2. Due to cutting off less impactful documents, only key representatives of each cluster are visualized.

\section{REFERENCES}

Aguinis, H., Cummings, C., Ramani, R., \& Cummings, T. G. (2019). An A is an A: the new bottom line for valuing academic research. Academy of Learning and Education, 34(1).

Ahl, H., \& Marlow, S. (2012). Exploring the dynamics of gender, feminism and entrepreneurship: advancing debate to escape a dead end. Organization, 19, 543-562.

Anzai, T., Kusama, R., Kodama, H., \& Sengoku, S. (2012). Holistic observation and monitoring of the impact of interdisciplinary academic research projects: An empirical assessment in Japan. Technovation, 32, 345-357.

Argyris, C. (1993). On the nature of actionable knowledge. The Psychologist, 6(1), 29-32.

Bailey, M., Dziewanowska, K., Harney, B., Mihelic, K., Pearce, A., \& Spencer, N. (2018). Beyond disciplines: can design approaches be used to develop education for jobs that don't yet exist? Proceedings of the E\&PDE 2018 20th International Conference on Engineering and Product Design, London.

Bailey, M., Harney, B. \& Pearce, A. (2019). Designing a design thinking approach to HRD. International Journal of HRD Practice, Policy and Research, 4(2), 9-23. doi: 10.22324/ ijhrdppr.4.202.

Bailey, M. \& Smith, N. (2010). Safe environments for innovation - developing a new multidisciplinary masters programme, in W. Boks et al. (Eds.) DS 62: Proceedings of E\&PDE 2010, the 12th International Conference on Engineering and Product Design Education - When Design Education and Design Research meet .... Strathclyde: The Design Society Institution of Engineering Designers, pp. 60-65.

Bailey, M., \& Smith, N. (2016). Making it work: integrated academic practice, in E. Boya (Ed.) Proceedings of 20th DMI: Academic Design Management Conference; Inflection Point: Design Research Meets Design Practice. Boston: The Design Management Institute, pp. 2346-2363.

Banks, G. C., Pollack, J. M., Bochantin, J. E., Kirkman, B. L., Whelpley, C. E., \& O’Boyle, E. H. (2016). Management's science-practice gap: a grand challenge for all stakeholders. Academy of Management Journal, 59(6), 2205-2231.

Bansal, P., Bertels, S., Ewart, T., MacConnachie, P., \& O'Brien, J. (2012). Bridging the research-practice gap. The Academy of Management Perspectives, 26, 73-92.

Baruch, Y., \& Rousseau, D. M. (2018). Integrating psychological contracts and ecosystems in career studies and management. Academy of Management Annals, 13(1), 84-111.

Biggs, J. (1998). Assessment \& classroom teaching: A role for summative assess. Assessment in Education, 5(1), 103-110.

Binder, J. (2016). Global Project Management: Communication, Collaboration and Management Across Borders, 2nd edition. London: Routledge.

Borgatti, S. P., Everett, M. G., \& Johnson, J. C. (2018). Analyzing Social Networks. London: Sage.

Brabrand, C., \& Dahl, B. (2009). Using the SOLO taxonomy to analyze competence progression of university science curricula. Higher Education, 58(4), 531-549.

Bridges, B. (1986). Western Europe and Korea: an awakening relationship, Global Economic Review, 15(2), 21-33, doi: 10.1080/12265088608422757. 
Briner, R. B. (1998). What is an evidence-based approach to practice and why do we need one in occupational psychology. Proceedings of the 1998 British Psychological Society Occupational Psychology Conference. The British Psychological Society, Leicester, UK, 39-44.

Burgelman, R.A. (1983a). A model of the interaction of strategic behaviour, corporate context and the concept of strategy, Academy of Management Review, 8(1), 61-70.

Burgelman, R. A. (1983b). Corporate entrepreneurship and strategic management: insights from a process study. Management Science, 29(12), 1349-1364.

Burgelman, R. A., \& Hitt, M. A. (2007). Entrepreneurial actions, innovation and appropriability. Strategic Entrepreneurship Journal, 1, 349-352.

Churchman, D., \& King, S. (2009). Academic practice in transition: Hidden stories of academic identities. Teaching in Higher Education, 14(5), 507-516.

Contractor, N. S., Wasserman, S., \& Faust, K. (2006). Testing multitheoretical, multilevel hypotheses about organizational networks: an analytic framework and empirical example. Academy of Management Review, 31(3), 681-703.

Craig, E., \& Hall, D. (2011). The new organizational career: too important to be left to HR? In R. J. Burke, \& C. L. Cooper (Eds.) Reinventing HRM: Challenges and New Directions. London: Routledge, pp. 115-132.

Crawley, M., \& O'Meara, L. (2002). Gender Impact Assessment Handbook. Belfast: Gender Equality Unity.

Crowley-Henry, M., Benson, E. T., \& Al Ariss, A. (2019). Linking talent management to traditional and boundaryless career orientations: research propositions and future directions. European Management Review, 16(1), 5-19.

D'este, P., \& Perkmann, M. (2011). Why do academics engage with industry? The entrepreneurial university and individual motivations. The Journal of Technology Transfer, 36(3), 316-339.

DeNisi, A. S., Wilson, M. S., \& Biteman, J. (2014). Research and practice in HRM: a historical perspective. Human Resource Management Review, 24, 219-231.

De Nooy, W., Mrvar, A., \& Batagelj, V. (2018). Exploratory Social Network Analysis with Pajek: Revised and Expanded Edition for Updated Software (Vol. 46). Cambridge: Cambridge University Press.

De Wit-de Vries, E., Dolfsma, W. A., van der Windt, H.J., \& Gerkema, M. P. (2018). Knowledge transfer in university-industry research partnerships: a review. The Journal of Technology Transfer, 1-20.

Dobrow, S. R., Chandler, D. E., Murphy, W. M., \& Kram, K. E. (2012). A review of developmental networks: incorporating a mutuality perspective. Journal of Management, 38(1), 210-242.

Donald, W. E., Baruch, Y., \& Ashleigh, M. (2019). The undergraduate self-perception of employability: human capital, careers advice, and career ownership. Studies in Higher Education, 44(4), 599-614.

Dziewanowska, K., Quan, R., \& Pearce, A. (2018). Capturing the value of international mobility in higher education. Global Entrepreneurial Talent Management Conference, University of Warsaw, Poland, April 17, 2018.

EPSRC (2019). Sandpits. https://epsrc.ukri.org/funding/applicationprocess/routes/network/ ideas/whatisasandpit/.

European Commission (2008). Entrepreneurship in Higher Education: Final report of the Expert Group. https://ec.europa.eu/growth/content/final-report-expert-group-entrepreneurship -higher-education-especially-within-non-business-0_en.

European Commission (2017). Research and Innovation Staff Exchange (RISE): Bridging R\&I Sectors in Europe and Worldwide. https://ec.europa.eu/research/mariecurieactions/ news/research-and-innovation-staff-exchange-rise-bridging-ri-sectors-europe-and -worldwide_en. 
European Commission (2019). Research and Innovation - Participant Portal 2020 Online Manual. http://ec.europa.eu/research/participants/docs/h2020-funding-guide/cross-cutting -issues/gender_en.htm.

Fayolle, A., Verzat, C., \& Wapshott, R. (2016). In quest of legitimacy: The theoretical and methodological foundations of entrepreneurship education research. International Small Business Journal, 34(7), 895-904.

Fortune \& SHRM (2001). Impact of diversity initiatives on the bottom line. A SHRM survey of the Fortune 1000 (S12-S14) in Keeping Your Edge: Managing a Diverse Corporate Culture. www.fortune.com/sections.

Fuller, J. (2016). How to hire a millennial. http://www.hbs.edu/recruiting/blog/post/how-to -hire-a-millennial.

Gubbins, C., Harney., B., van der Werff, L., \& Rousseau, D. M. (2018). Enhancing the trustworthiness and credibility of HRD: evidence-based management to the rescue? Human Resource Development Quarterly, 29(3), 193-202.

Guo, Y., Gao, H., Cai, Z., Zhang, S., \& Hu, F. (2018). Continuous improvement of industrial engineering education based on PDCA method and structural importance. Proceeding of the 2018 IEEE IEE International Conference on Industrial Engineering and Engineering Management, Bangkok, Thailand, December 2018.

Harney, B., Monks, K., Alexopoulos, A., Buckley, F., \& Hogan, T. (2014). Research scientists as knowledge workers: contract status and employment opportunities. International Journal of Human Resource Management, 25(16), 2219-2233.

Herr, K., \& Anderson, G. L. (2005). The Action Research Dissertation: A Guide for Students \& Faculty. Thousand Oaks: Sage.

Hollensbe, E., Wookey, C., Hickey, L., George, G., \& Nichols, C. V. (2014). Organizations with purpose. Academy of Management Journal, 57(5), 1227-1234.

Holquist, E., \& Sundin, C. (1991). The growth of women's entrepreneurship - push or pull factors? Paper presented to the European Institute for Advanced Studies in Management Conference on Small Business, University of Durham Business School. http://www.EIASM.be.

International Association of University (IAU) (2010). Internationalisation of higher education: An evolving landscape, locality and globally. https://www.iau-aiu.net/Global-survey-onInternationalization.

Jimenez-Jimenez, D., Martinez-Costa, M., Martinez-Lorente, A. R., \& Ahmed Dine Rabeh, H. (2015). Total quality management performance in multinational companies, a learning perspective. The TQM Journal, 27(3), 328-340.

Kaše, R., Dries, N., Briscoe, J. P., Cotton, R. D., Apospori, E., Bagdadli, S., Çakmak-Otluoğlu, K. Ö., Chudzikowski, K., Dysvik, A., Gianecchini, M., Saxena, R., Shen, Y., Verbruggen, M., Adeleye, I., Babalola, O., Casado, T., Cerdin, J.-L., Kim, N., Mishra, S. K., Unite, J., \& Fei, Z. (2020). Career success schemas and their contextual embeddedness: a comparative configurational perspective. Human Resource Management Journal, 30(3), 422-440. doi: 10.1111/1748-8583.12218.

König, B., Diehl, K., Tscherning, K. and Helming, K. (2013). A framework for structuring interdisciplinary research management. Research Policy, 42, 261-272.

Kossek, E. E., Lobel, S. A., \& Brown, J. (2006). Human resource strategies to manage workforce diversity: examining "the business case," in P. Prasad, \& J. K. Pringle (Eds.) Handbook of Workplace Diversity. London: Sage, pp. 53-74.

Koulopoulos, T., \& Keldsen, D. (2014). The Gen Z Effect: The Six Forces Shaping the Future Of Business. Brookline, MA: Bibliomotion Inc.

Lea, M. R., \& Stierer, B. (2011). Changing academic identities in changing academic workplaces: Learning from academics' everyday professional writing practices. Teaching in Higher Education, 16(6), 605-616. 
Leenders, R., van Engelen, J., \& Kratzer, J. (2003). Virtuality, communication, and new product team creativity: a social network perspective. Journal of Engineering and Technology Management, 20(1-2), 69-92.

Marginson, S., \& van der Wende, M. (2007). Globalisation \& Higher Education, Education Working Paper No.8, Centre for Educational Research and Innovation (CERI), OECD Directorate for Education. www.oecd-ilibrary.org/education/oecd-education-working -papers.

Markee, N. (1997). Managing Curricular Innovation. Cambridge: Cambridge University Press.

Marlow, S., \& Martinez Dy, M. (2018). Is it time to rethink the gender agenda in entrepreneurship research? International Business Journal, 36, 3-22.

Mascarenhas, C., Ferreira, J. J., \& Marques, C. (2018). University-industry cooperation: a systematic literature review and research agenda. Science and Public Policy, 45(5), 708-718.

Neeley, T. (2015). Global teams that work. Harvard Business Review, 93(10), 74-81.

Partha, D., \& David, P. A. (1994). Toward a new economics of science. Research Policy, 23(5), 487-521.

Pearce, A., \& Quan, R. (2015). International staff mobility in higher education: to what extent could intra-European entrepreneurial approach be applied to Sino-CEE initiatives? Journal of East European Management Studies, 20(2), 226-254.

Pfeffer, J., \& Sutton, R. I. (2006). Hard Facts, Dangerous Half-Truths and Total Nonsense: Profiting from Evidence-Based Management. Boston, MA: Harvard University Press.

Quan, R., Smailes, J., \& Fraser, W. (2013). The transition experiences of direct entrants from overseas higher education partners into UK universities. Teaching in Higher Education, 18(4), 414-426.

Reason, P., \& Bradbury, H. (2006). Preface to The Handbook of Action Research: the Concise Paperback Edition, London: Sage, pp. xxi-xxxii.

Reed, M. (2016). The Research Impact Handbook. Huntly, UK: Fast Track Impact.

Richardson, J., \& Zikic, J. (2007). The darker side of an international academic career. Career Development International, 12(2), 164-186.

Rouse, E. (2019). Where you end and I begin: understanding intimate co-creation. Academy of Management Review, 45(1), 181-204. https://journals.aom.org/doi/10.5465/amr.2016 .0388 .

Rousseau, D. M. (2012). The Oxford Handbook of Evidence-Based Management. Oxford: Oxford University Press.

Sánchez-Fernández R., \& Iniesta-Bonillo, M. A. (2006). Consumer perception of value: Literature review and a new conceptual framework. Journal of Consumer Satisfaction, Dissatisfaction and Complaining Behavior, 19(1), 40-58.

Sanders, E. B. N. and Stappers, P. J. (2008). Co-creation and the new landscapes of design. Co-design, 4(1), 5-18.

Smith, K. G., \& DiGregorio D. (2002). Bisociation, discovery, and the role of entrepreneurial action, in M. A. Hitt, R. D. Ireland, S. M. Camp, \& D. L. Sexton (Eds.) Strategic Entrepreneurship: Creating a New Mindset. Oxford: Blackwell Publishers, pp. 129-150.

Stanford University (2019). Gendered Innovations. http://genderedinnovations.stanford.edu/ what-is-gendered-innovations.html.

Taha, N., \& Cox, A. (2016). Social network dynamics in international students' learning. Studies in Higher Education, 41(1), 182-198.

Thornberry, N. (2001). Corporate entrepreneurship: antidote or oxymoron?, European Management Journal, 19(5), 526-533.

Tkachenko, O., Hahn, H.-J., \& Peterson, S. (2016). Theorizing the research-practice gap in the field of management: a review of key frameworks and models, in C. Hughes, \& M. W. Gosney (Eds.) Bridging the Scholar-Practitioner Gap in Human Resources Development. Hershey, PA: IGI Global, pp. 101-119. 
Van Raan, A. (2005). For your citations only? Hot topics in bibliometric analysis. Measurement: Interdisciplinary Research and Perspectives, 3(1), 50-62.

Van Rijnsoever, F. J., \& Hessels, L. K. (2011). Factors associated with disciplinary and interdisciplinary research collaboration. Research Policy, 40, 463-472.

Vogel, R. (2012). The visible colleges of management and organization studies: a bibliometric analysis of academic journals. Organization Studies, 33(8), 1015-1043.

Voss, C. (2019). Guidepost: towards an actionable and pragmatic view of impact. Academy of Management Discoveries, AMD-2019-0113.

Warkentin, M., \& Beranek, M. (1999). Training to improve virtual team communication. Information Systems Journal, 9(4), 271-290.

Wiklund, J., Wright, M., \& Zahra, S. A. (2019). Conquering relevance: entrepreneurship research's grand challenge. Entrepreneurship Theory and Practice, 43(3), 419-436. doi: 1042258718807478.

World Economic Forum. (2018). Future of Jobs Report 2018. Geneva: Centre for the New Economy and Society.

Zacher, H., Rudolph, C. W., Todorovic, T., \& Amman, D. (2019). Academic career development: a review and research agenda. Journal of Vocational Behaviour, 110, 357-373. https://doi.org/10.1016/j.jvb.2018.08.006.

Zupic, I., \& Cater, T. (2015). Bibliometric methods in management and organization. Organizational Research Methods, 18(3), 429-472. 